\title{
Correlation between Mid Upper Arm Muscle Area/Size and Muscle Strength
}

\author{
Tan Yong Bin, ${ }^{1}$ Vitriana, ${ }^{2}$ Titing Nurhayati ${ }^{3}$ \\ ${ }^{1}$ Faculty of Medicine, Universitas Padjadjaran, ${ }^{2}$ Department of Physical Medicine and Rehabilition \\ Faculty of Medicine Universitas Padjadjaran/Dr. Hasan Sadikin General Hospital Bandung \\ ${ }^{3}$ Department of Cardiovascular Faculty of Medicine Universitas Padjadjaran/Dr. Hasan Sadikin \\ General Hospital Bandung
}

\begin{abstract}
Background: Muscle area/size reflects the true magnitude of muscle tissue changes. Muscle strength is an active tension generated by muscle that depends on its capacity to exert force on an object. The relation between the quantity of muscle area and the amount of muscle strength is suggested. The aim of this study was to analyze the correlation between mid-upper arm muscle area/size and muscular strength.

Methods: This analytic study with ten subjects (medical students) who met the inclusion and exclusion criteriawas conducted at the Faculty of Medicine Universitas Padjadjaran in Jatinangor campus from $22^{\text {th }}$ of April to $1^{\text {st }}$ of November 2014. A skinfold calliper was used to measure triceps skinfold while a measuring tape measured the mid-upper arm circumference and a dynamometer measured the muscle strength. A formula was used to determine the mid-upper arm muscle area/size using mid-upper arm circumference and triceps skinfold. The collected data were analyzed statistically using correlation test and simple linear regression.
\end{abstract}

Results: There was a strong correlation between mid-upper arm muscle area/size and muscular strength (correlation cooefficient 0.746). Moreover, the higher the Body Mass Index, the stronger the muscle strength was to some point. If the BMI was more than $25 \mathrm{~kg} / \mathrm{m}^{2}$, this findings did not occurred.

Conclusions: There is a strong positive correlation between mid-upper arm muscle area/size and arm muscle strength. [AMJ.2016;3(4):590-5]

Keywords: Mid-upper arm, muscle area/size, muscle strength

\section{Introduction}

Muscle is an organ that produces movement of an organism by contractions. ${ }^{1}$ Muscular strength is produced by contraction of muscles. It is the ability of an animal or human to exert force on physical objects using muscle depends on its capacity to generate active tension. $^{2}$ Mid upper arm muscle area reflects the true magnitude of muscle tissue changes. ${ }^{3}$ Training the muscle to increase its area can have many advantages, among others is in preventing limb muscle dysfunction in chronic obstructive pulmonary disorder. ${ }^{4}$

It is widely accepted that the muscle force produced is directly proportional to its crosssectional area. Ikai and Fukunaga ${ }^{5}$ discovered that there was a positive relationship between cross-sectional area and maximum isometric strength of musculus biceps brachii. Somehow,
Brad Jon's study showed that a small to moderate muscle hypertrophy did not have significant effect on muscle strength. ${ }^{6}$ This contradiction leads to the need of this study.

This study was conducted among medical students from the Faculty of Medicine Universitas Padjadjaran to discover the correlation between mid-upper arm muscle area and muscular strength.

\section{Methods}

This study was carried out using an analytic study with numeric variables of independent and dependent variables.

The study population was the medical students in the Faculty of Medicine Universitas Padjadjaran and was conducted at the Faculty of Medicine Universitas Padjadjaran, in Jatinangor campus from $22^{\text {th }}$ of April to $1^{\text {st }}$ of

Correspondence: Tan Yong Bin, Faculty of Medicine, Universitas Padjadjaran, Jalan Raya Bandung-Sumedang Km.21, Jatinangor, Sumedang, Indonesia, Phone: +6287827571509 Email: y1b2t3a4n5@gmail.com 
November 2014.

The random sampling method was used in this study. A total of 10 medical students/ subjects based on the sample size calculation and who met the inclusion criteria participated in this study. The inclusion criteria of the subject selections were male, age 18-25 years, normal healthy status, body mass index within normal weight to overweight, and agreed to participate in this study by signing the informed consent. The exclusion criteria were a person with arm impairment and disability which caused he/she could not do the test, drug user such as hormones, fatigue and alcoholic.

Furthermore, body mass index was calculated as weight divided by height squared. Body mass index $20 \mathrm{~kg} / \mathrm{m}^{2}$ and below was defined as underweight, normal weight was $18.5-24.9 \mathrm{~kg} / \mathrm{m}^{2}$, overweight was $25-29.9 \mathrm{~kg} / \mathrm{m} 2$ and obesity was above $30 \mathrm{~kg} /$ $\mathrm{m}^{2}{ }^{7}$ The normal value of triceps skin fold for normal weight men was $12.0 \mathrm{~mm}$ (standard deviation: $0.5 \mathrm{~mm}$ ) and for overweight men was $18.2 \mathrm{~mm}$ (standard deviation: $0.6 \mathrm{~mm}$ ). ${ }^{7}$ The normative mean value for muscle strength was 265 Newton (standard deviation:38) for male. ${ }^{8}$ Moreover, fatigue was defined as a feeling of lack of energy, weariness and aversion to effort. The assessment of fatigue was through interviewing. ${ }^{10}$ Muscle fatigue is a decline in muscle performance associated with muscle activity. Prolonged high-frequency stimulation applied focally to only one region of a muscle fibre produces greater and faster loss of force than does stimulation applied all along fibre which failure of longitudinal action potential transmission is an important fatigue mechanism. ${ }^{11}$ The subjects were asked whether they performed any vigorous physical activity in the previous 2 hours.

The data was collected with the hand held dynamometer readings (recorded in Newton), callipers and measuring tapes. The mid-upper arm muscle area was calculated through the formula involving mid-upper arm circumference and triceps skin-fold.

Furthermore, the subjects were prepared before the test and were made sure that they did not have vigorous physical activity in the previous 2 hours and were in good health status and well condition. The subjects' basic information was collected and informed consent. Next, the subjects were required to lie down on a flat surface bed. Then, the midupper arm circumference was measured with a measuring tape. First, the midpoint of the upper-arm was defined by the location of the

$$
n=\left(\frac{\left(Z_{1-\alpha}+Z_{1-\beta}\right)}{0.5 \operatorname{In}\left[\frac{1+r}{1-r}\right]}\right)^{2}+3
$$

\section{Figure 1 The Formula to Calculate Mid- upper Arm Muscle Area}

shoulder and tip of the elbow by bending the elbow 90 degree. The tape was placed at the tip of the shoulder to the elbow and marked the midpoint. Then, the measuring tape was measured around the mid-upper arm between the shoulder and the tip of the elbow while arm lay beside the side of body and relaxed.

After measuring the mid-upper arm, the subject was measured for triceps skinfold by the caliper. Then, the midpoint of the upper arm was defined. The fold of skin with underlying fat was pulled out and held with thumb and index finger as a c-shaped. With the caliper in the other hand, the jaws of the caliper were placed on the skin-folds about $7.5 \mathrm{~mm}$ away from the measuring thumb. The trigger of the caliper was released and the measurement was read within 5 seconds. The fingers or caliper should not be released before the reading of the measurement. The procedure was repeated for 3 times to get the average results.

The subject was stabilized on superior aspect of shoulder or arm. The limb position was set as shoulder in neutral with elbow flexed 90 degree and the forearm in neutral. The dynamometer was placed just proximal to styloid process on the dominant arm. The subject was requested to flex his/her elbow against the dynamometer fixed on the tester's hand and resisted the movement. The maximum flexing force was encouraged by the tester through words. The action of testing procedure was practiced for a few times until subjects were able to do it correctly. The test was conducted twice at the same side. The reading was recorded in Newton $(\mathrm{N})$.

The collected data were analyzed using correlation test and simple linear regression. Ethical clearance was agreed by the Health Research Ethics Committee, Faculty of Medicine Universitas Padjadjaran.

\section{Results}

The subjects were apparently healthy men 
Table 1 Table of Physical Characteristic of Subjects

\begin{tabular}{lcc}
\hline \multicolumn{1}{c}{ Characteristics } & Mean & Standard Deviation \\
\hline Age $(\mathrm{y})$ & 21.9 & 0.875 \\
Weight $(\mathrm{kg})$ & 70.7 & 12.302 \\
Height $(\mathrm{cm})$ & 171.8 & 7.405 \\
Body mass Index $(\mathrm{kg} / \mathrm{m} 2)$ & 23.9 & 3.311 \\
Mid-upper arm circumference $(\mathrm{cm})$ & 31.4 & 3.315 \\
Triceps skinfold $(\mathrm{cm})$ & 1.87 & 0.795 \\
Mid-upper arm muscle area/size $(\mathrm{cm} 2)$ & 51.51 & 8.828 \\
Muscle strength(N) & 238.74 & 25.708 \\
\hline
\end{tabular}

with a mean age of 21.9 years. Their mean Body Mass Index (BMI) was laid in normal weight category. The mean measurement for mid-upper arm circumference was 31.4, triceps skin folds was 1.87, mid-upper arm muscle area was 51.51 and muscle strength was 238.74 (Table 1 ).

The statistical test of this study revealed that there was a strong positive correlation (The Pearson correlation coefficient was 0.746) between arm muscle area/size and arm muscle strength. Moreover, by using simple linear regression test, it showed that the higher the BMI, the stronger the muscle strength to some point was. If the BMI was more than $25 \mathrm{~kg} / \mathrm{m}^{2}$, this findings did not occurred (Figure 1).

\section{Discussion}

The initial findings in this study showed that there was a positive correlation between mid-upper arm muscle area/size and muscle strength, meaning that the more mid-upper arm muscle area/size will produce more arm muscle strength. A study by Newman et al. ${ }^{12}$ stated that muscle strength was closely related to the absolute quantity of muscle mass. This statement was parallel with the study of Abe et al. ${ }^{13}$ who reported that the combination of resistance training and kaatsu-walk training, would increase the muscle cross sectional area

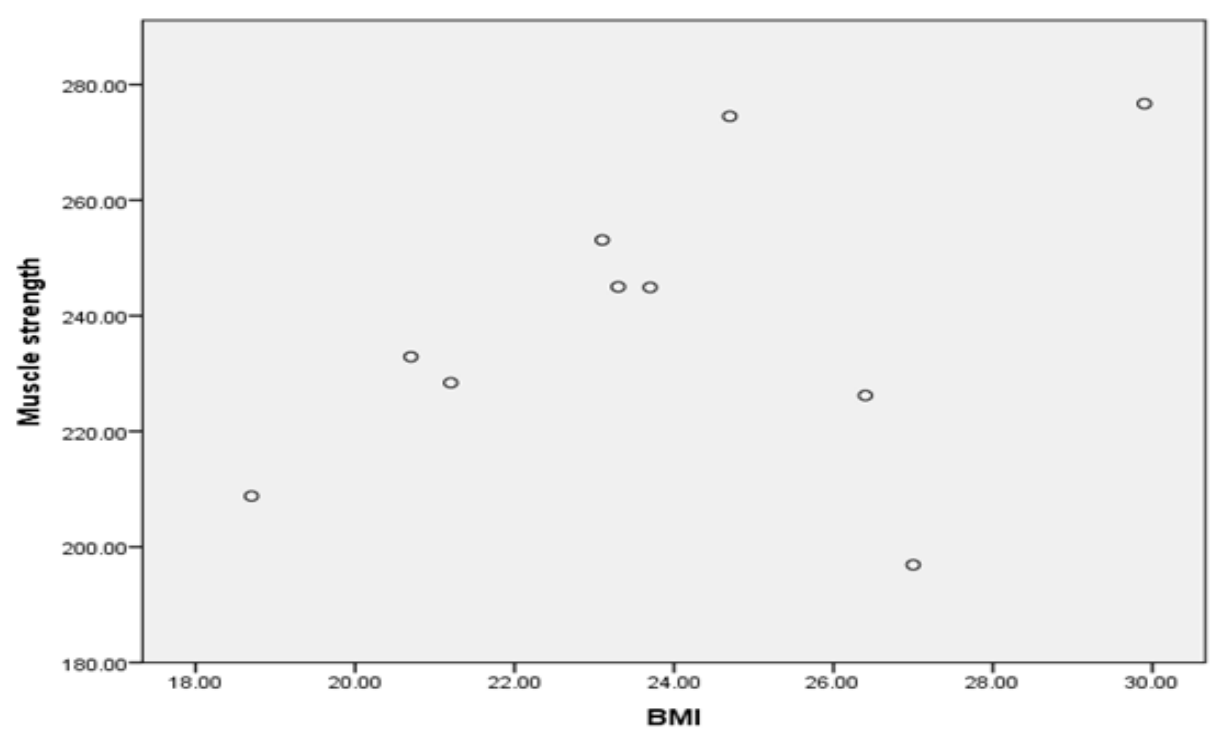

Figure 2 Scatter Plot of The Correlation between Body Mass Index and Muscle Strength 
$(4-7 \%)$ and at the same time one repetition maximum isometric strength was increased $(8-10 \%)$. Those studies strengthened the relationship between muscle size and muscle strength.

The positive correlation between muscle size and muscle strength could explain a phenomenon that occurred in the elderly. A study by Goodpaster et al. ${ }^{14}$ reported that the reduced muscle mass leads to age-related decline of strength in older adults. The muscle weakness decreases older adults' basic life function and diminishes physical activity. The loss of muscle mass was both the cause and the result of the loss of strength. ${ }^{14}$

In this study, a contradictory findings was discovered. Some subjects with higher mid-upper arm area muscle $\left(55.3 \mathrm{~cm}^{2}\right)$, had lower muscle strength compared to those with lower muscle arm area $\left(49.8 \mathrm{~cm}^{2}\right)$. It was suspected that to reach a certain value of muscle strength could be influenced by many factors. One of the factors was physical activity. Physical activity was associated with the increase of muscle strength despite the muscle mass. Hughes et al. ${ }^{15}$ discovered that a certain level of physical activity has a direct effect on muscle strength. People with regular physical activity expenditure rate will have more muscle strength than those without. ${ }^{14}$ It could be presumed that the subjects who had higher muscle arm area and lower muscle strength compared to other subjects used to exercise periodically, but stopped for unknown reasons. Due to young age, the muscle mass/ size did not reduce.

Not all studies had the same results as this study. According to Callaghan et al. ${ }^{16}$, who conducted a study about the existence of quadriceps atrophy in patellofemoral pain syndrome, stated that muscle strength may not be related to muscle size. It could be other factors that cause this difference. ${ }^{16}$ It was suspected that patients with patellofemoral pain syndrome had more reduction in muscle strength. This condition was not due to decrease of the muscle size but painful sensation resisted its movement while having muscle peak torque testing. So, pain may be one of the factors that influence muscle strength.

In this study, the overweight and obese subjects could show lower muscle strength and muscle size than those who were normal weight. People with overweight and obese have different skeletal muscle structure and function than normal weight people, such as less type I and more type II muscle fibers, impaired muscle oxidative capacity, lower fuel utilization and increase lipid accumulation. It showed that at the same body mass, overweight subjects had lesser muscle voluntary contractions and muscle strength. Obese people had less peripheral muscle strength than those who were normal weight. Excess adiposity could limit muscle strength gains due to hyper production of proinflamatory cytokines in obesity impairs glucose disposal in muscle. ${ }^{7}$

There were some limitations in this study. Some technical difficulties such as the rigid dynamometer placement sites, which would cause reflex of subjects to reduce maximum force in order to prevent pain. The calculation of muscle area was less reliable than measuring muscle area using magnetic resonance imaging. Moreover, this study was limited to the subjects from medical students with small sample size, so the results could not be generalized to the general population.

It can be concluded that there is a strong positive correlation between mid-upper arm muscle area/size and muscle strength. The higher the mid-upper arm muscle area/size, the stronger the muscle arm will be.

Recommendation from this study is that healthy individuals should maintain or improve muscle area to improve muscle strength by resistance exercise 3 times a week. Individuals restricted by disease can perform light exercise and simple cardio workouts according to their body conditions. Future study can include the general population and conduct in a wide scale to get more accurate and reliable results. Additionally, there are many more factors that may interfere with the result such as tools and equipment. Magnetic Resonance imaging scan can be used to find the muscle area precisely. Peak torque, isokinetic dynamometer, resistance testing can be used to measure muscle strength.

\section{References}

1. Dorland WAN. Dorland's illustrated medical dictionary. 28th ed. Philadelphia: Saunders;2008.

2. Houglum PA, Berttoti DB, editors. Muscle activity and strength. Brunnstrom's clinical kinesiology. 6th ed. Philadelphia, PA: F.A. Davis Company; 2012. p.126-55

3. Chomtho S, Fewtrell MS, Jaffe A, Williams JE, Wells JC. Evaluation of arm anthropometry for assessing pediatric body composition: evidence from healthy and sick children. Pediatr Res. 2006;59(6):860-5. 
4. Maltais F, Decramer M, Casaburi R, Barreiro E, Burelle Y, Debigare R, et al. An official American Thoracic Society/European Respiratory Society statement: update on limb muscle dysfunction in chronic obstructive pulmonary disease. Am J Respir Crit Care Med. 2014;189(9):e15-62

5. Waugh C, Blazevich A, Fath F, Korff T. Age-related changes in mechanical properties of the Achilles tendon. J Anat. 2012;220(2):144-55.

6. Schoenfeld BJ, Aragon AA, Krieger JW. The effect of protein timing on muscle strength and hypertrophy: a meta-analysis. J Int Soc Sports Nutr. 2013;10(1):53.

7. Pescatello LS, Kelsey BK, Price TB, Seip RL, Angelopoulos TJ, Clarkson PM, et al. The muscle strength and size response to upper arm, unilateral resistance training among adults who are overweight and obese. J Strength Cond Res. 2007;21(2):307-13.

8. Woods JL, Iuliano-Burns S, King SJ, Strauss BJ, Walker KZ. Poor physical function in elderly women in low-level aged care is related to muscle strength rather than to measures of sarcopenia. Clin Interv Aging. 2011;6:67-76.

9. Akagi R, Takai Y, Ohta M, Kanehisa H, Kawakami Y, Fukunaga T. Muscle volume compared to cross-sectional area is more appropriate for evaluating muscle strength in young and elderly individuals. Age Ageing. 2009;38(5):564-9.

10. Mead G, Lynch J, Greig C, Young A, Lewis $S$, Sharpe M. Evaluation of fatigue scales in stroke patients. Stroke. 2007;38(7):20905.

11. Allen DG, Lamb G, Westerblad H. Skeletal muscle fatigue: cellular mechanisms. Physiol Rev. 2008;88(1):287-332.

12. Newman $A B$, Kupelian $V$, Visser M, Simonsick EM, Goodpaster BH, Kritchevsky SB, et al. Strength, but not muscle mass, is associated with mortality in the health, aging and body composition study cohort. J Gerontol A Biol Sci Med Sci. 2006;61(1):72-7.

13. Abe T, Kearns CF, Sato Y. Muscle size and strength are increased following walk training with restricted venous blood flow from the leg muscle, Kaatsu-walk training. J Appl Physiol (1985). 2006;100(5):14606

14. Goodpaster BH, Park SW, Harris TB, Kritchevsky SB, Nevitt M, et al. The loss of skeletal muscle strength, mass, and quality in older adults: the health, aging and body composition study. J Gerontol A Biol Sci Med Sci. 2006;61(10):1059-64.

15. Hughes VA, Frontera WR, Wood M, Evans WJ, Dallal GE, Roubenoff R, Singh MA. Longitudinal muscle strength changes in older adults: influence of muscle mass, physical activity, and health. J Gerontol A Biol Sci Med Sci. 2001;56(5):B209-17.

16. Callaghan M, Oldham J. Quadriceps atrophy: to what extent does it exist in patellofemoral pain syndrome. Br J Sports Med. 2004;38(3):295-9. 


\title{
Health Belief Model Theory Application on Voluntary Counseling and Testing among Homosexual Men in Bandung Greater Area
}

\author{
Argya Nareswara, ${ }^{1}$ Chrysanti Murad, ${ }^{2}$ Irvan Afriandi ${ }^{3}$ \\ ${ }^{1}$ Faculty of Medicine Universitas Padjadjaran, ${ }^{2}$ Department of Microbiology Faculty of Medicine \\ Universitas Padjadjaran, ${ }^{3}$ Department of Public Health Faculty of Medicine Universitas \\ Padjadjaran
}

\begin{abstract}
Background: The number of human immunodeficiency virus (HIV) cases is high and is constantly increasing. Homosexual men as a transmission niche is not only significant in terms of numbers, but also in natural aspects of anal sex, tropism of HIV-1, and high-risk behavior. Voluntary Counseling and Testing (VCT) is important for accelerating diagnosis and management plan; yet the uptake on high-risk population in Indonesia is low. A behavior-reasoning theory, Health Belief Model (HBM), attempts to explain whether or not individuals engage in certain health behavior. This study tries to assess participation rate of VCT, to portray HBM variables perception, and to depict significance of HBM variables towards VCT uptake or VCT intention.

Methods: This study was conducted in October-November 2014 using cross-sectional design; 127 respondents were gathered according to Respondent Driven Snowball Sampling. This study used an internet-based questionnaire derived from Champion's 1984 mammogram HBM questionnaire. Privacy and compensation were obtained. The Chi square test and logistic regression of HBM variables were done.

Results: The VCT uptake was low (15.7\%). Certain sexual experience and commitment were significant (Commitment to Men $\mathrm{p}=0.027$, Oral Sex experience with men $\mathrm{p}=0.001$, Anal Sex Experience with men $\mathrm{p}=0.038$ ). Chi Square test revealed significance on Perceived Susceptibility, Perceived Benefit, and Cues to Action.

Conclusions: Uptake of VCT is considerably low compared with total high risk population and other similar studies. Personal Susceptibility to HIV/AIDS is recommended to be emphasized; while VCT Benefit and Cues to Action in young homosexual men communities are better encouraged. [AMJ.2016;3(4):595-604]
\end{abstract}

Keywords: Health Belief Model, HIV, Homosexual, VCT

\section{Introduction}

Since 2014, infection of human immunodeficiency virus (HIV) has been a global problem that has not been solved. With 30.000 .000 positive individuals globally and 2.500.000 global case incidence per year, the number of HIV-positive individual is increasing day by day. ${ }^{1}$ In Indonesia, the prevalence of HIV Infection has reached $0.2 \%$ among general population. In addition, cumulative HIV cases reported until June 2012 reached 86.762 cases, whereas cumulative Acquired Immunodeficiency Syndrome (AIDS) cases reported from 1987 until June 2012 was 32.103 cases. $^{2,3}$

Homosexual men are considered more susceptible to be infected by HIV because of HIV-1 tropism in large intestine endothelial cells, low condom usage, and high promiscuity which make the odds of being infected by HIV 18.7 times higher compared with those in heteronormative adult population in Asia. ${ }^{1,4-8}$ With the lowest estimation of $2.2 \%$ proportion from the total male population, men who have sex with men (MSM) is HIV-transmitting niche that is quite big. ${ }^{9}$ In Indonesia, for instance, HIV/AIDS is positive in around $2.1 \%$ MSM in Bandung, 5.6\% in Surabaya, and $8.1 \%$ in Jakarta. ${ }^{10}$

Voluntary counseling and testing (VCT) is a serial of rapid test, education, and counseling regarding HIV/AIDS intended to helping individuals to know their HIV status, to understand the behavior they might

Correspondence: Argya Nareswara, Faculty of Medicine, Universitas Padjadjaran, Jalan Raya Bandung-Sumedang Km.21, Jatinangor, Sumedang, Indonesia, Phone: +6289656067175 Email: rgynrswr@gmail.com 